\title{
The Use of T1 Sagittal Angle in Predicting Cervical Disc Degeneration
}

\author{
Bong-Seok Yang ${ }^{1}$, Su-Keon Lee ${ }^{1}$, Kyung-Sub Song ${ }^{1}$, Sang-Pil Yoon ${ }^{1}$, Geun Jang ${ }^{1}$, \\ Chae-Chul Lee ${ }^{1}$, Seong-Hwan Moon ${ }^{2}$, Hwan-Mo Lee ${ }^{2}$, Seung-Hwan Lee ${ }^{1}$ \\ ${ }^{1}$ Department of Orthopaedic Surgery, Gwangmyeong Sungae Hospital, Gwangmyeong, Korea \\ ${ }^{2}$ Department of Orthopaedic Surgery, Yonsei University College of Medicine, Seoul, Korea
}

\section{Study Design: Retrospective evaluation.}

Purpose: To analyze the effect of $\mathrm{T} 1$ slope on degree of degeneration in patients with cervical disc degeneration.

Overview of Literature: The T1 slope is well known parameter that may be very useful in evaluating sagittal balance. There are no reports on the analysis of the relationship between $\mathrm{T} 1$ slope and cervical disc degeneration. We hypothesized that $\mathrm{T} 1$ slope has an effect on the degree of cervical degeneration.

Methods: Sixty patients who had cervical spine magnetic resonance imaging (MRI) in our orthopedic clinic were enrolled. Patients were divided into two groups according to T1 slope. Radiologic parameters obtained from radiography and cervical spine MRI were compared between low T1 slope group ( $\leq 25$ ) and high T1 slope group (>25).

Results: Among low T1 slope group, average degeneration grade of each cervical segment was 2.65 in C2-3, 2.50 in C3-4, 2.62 in C4-5, 3.23 in C5-6, and 2.81 in C6-7. And that of high T1 group was 2.35 in C2-3, 2.32 in C3-4, 2.59 in C4-5, 2.79 in C5-6, and 2.32 in C6-7. Grade of degeneration of low T1 group was significantly higher, as compared with high T1 group in C5-6 ( $p=0.028)$ and C6-7 ( $p=0.009)$. Percentage of high grade degeneration of more than grand III was $65.4 \%$ in low $\mathrm{T} 1$ group and $32.4 \%$ in high $\mathrm{T} 1$ group $(p=0.018)$. Risk of high grade degeneration of $\mathrm{C} 6-7$ was significantly higher in low $\mathrm{T} 1$ group (odds ratio, 5.63; $95 \%$ confidence interval, $1.665-19.057 ; p=0.005)$

Conclusions: Patients with low T1 slope had higher grade of degeneration regardless of age and gender. Low T1 slope is a potential risk factor of cervical spondylosis especially in the C6-7 cervical segment.

Keywords: Intervertebral disc degeneration; Cervical spine; T1 slope; Magnetic resonance imaging

\section{Introduction}

Normal lordotic alignment is one of the most important contributing factors to effective motion and function of the cervical spine. Loss of normal lordotic alignment may induce pathologic changes in the kinematics and accelerate degeneration of the functional motion unit [1].
The T1 slope is the sagittal angle between a horizontal line and the superior end plate of T1. The T1 slope is well known parameter that may be very useful in evaluating sagittal balance. Knott et al. [2] reported that patients with T1 tilt of higher than $25^{\circ}$ need full column radiography because of the possibility of positive sagittal balance. T1 slope reportedly can be a predictor of kyphotic alignment

Received Jan 17, 2015; Revised Feb 12, 2015; Accepted Feb 12, 2015

Corresponding author: Seung-Hwan Lee

Department of Orthopaedic Surgery, Gwangmyeong Sungae Hospital, 36 Digital-ro, Gwangmyeong 14241, Korea

Tel: +82-2-2680-7699, Fax:+82-2-2680-7755, E-mail: java5885@gmail.com 
change after laminoplasty [3]. Cervical spondylosis is an age related degenerative change of cervical segments. Park et al. [4] reported that $\mathrm{T} 1$ sagittal slope angle decreased in the older group, as compared with the younger counter part. Many studies have evaluated the factor of cervical disc degeneration [1,5-11]. However, there are no studies on the relationship between T1 slope and cervical spondylosis.

We hypothesized that $\mathrm{T} 1$ slope can affect the degree of cervical degeneration because of impaired sagittal balance.

\section{Materials and Methods}

We enrolled patient of $>50$ years of age who had cervical spine magnetic resonance imaging (MRI) from January 2013 to December 2014 who visited our orthopedic clinic consecutively. Total 90 patients were enrolled at the beginning of study. Chart reviews indicated that neck pain, shoulder pain, and arm pain were the main symptoms. We excluded patients who taken cervical MRI due to motor vehicle accident or trauma because these traumatic event can cause change of natural cervical lordosis. Thirty patients were excluded and cervical spine MRI of $60 \mathrm{pa}-$ tients were included in the final analysis.

Patients were divided into two groups according to T1 slope. Radiologic parameters obtained from radiography and cervical spine MRI were compared between low T1 slope group $(<25)$ and high T1 slope group (>25).

\section{Inclusion criteria}

The patients who visited orthopaedic clinic of GwangMyeong Sung-Ae Hospital with (1) age above 50 years old, (2) no history of surgery on spine, (3) no recent history of trauma within 3 months, (4) patient with neck pain and radiculopathy of upper extremities, were included. Average age of all patients was $59.67 \pm 5.45$ years old. Average T1 slope was $26.65^{\circ} \pm 7.22^{\circ}$ and average cervical lordosis was $19.82^{\circ} \pm 10.42^{\circ}$. Of 60 patients, 30 were male and 30 were female (Table 1).

\section{Measures analyzed}

Lateral radiograph of the cervical spine was obtained in a standing position with the upper extremities attached naturally at the side of the trunk and their head facing
Table 1. Descriptive data of patients

\begin{tabular}{lc} 
Variable & Mean \pm standard deviation \\
\hline Age $(\mathrm{yr})$ & $59.67 \pm 5.45$ \\
Weight $(\mathrm{kg})$ & $61.55 \pm 7.07$ \\
\hline Height $(\mathrm{cm})$ & $162.90 \pm 7.08$ \\
\hline Body mass index $\left(\mathrm{kg} / \mathrm{m}^{2}\right)$ & $23.22 \pm 2.58$ \\
\hline T1 slope $\left(^{\circ}\right)$ & $26.65 \pm 7.22$ \\
Cervical lordosis $\left(^{\circ}\right)$ & $19.82 \pm 10.42$ \\
Sex (male:female) & $30: 30$ \\
\hline
\end{tabular}

forward for horizontal gaze.

T1 slope was measured as the angle between a horizontal line and superior endplate of $\mathrm{T} 1 \mathrm{in}$ standing lateral radiograph. Cervical lordosis was measured between lower end plate of $\mathrm{C} 2$ and inferior end plate of $\mathrm{C} 7$ in the same standing lateral radiograph.

Cervical intervertebral disc degeneration was measured based on the magnetic resonance imaging-based grading system [12]. Grading of disc degeneration of the 60 patients was performed by three spinal surgeons (observers) in a blinded fashion using the T2-weighted sagittal images. Five cervical levels (C2-3, C3-4, C4-5, C5-6, and C6-7) were chosen and 300 discs were assessed on T2weighted mid sagittal images.

This classification takes into account the nucleus signal intensity, the nucleus structure, the distinction between the nucleus pulposus and the annulus fibrosus, and the disc height from grade I to V. High grade degeneration was defined as a grade higher than grade III in which case the disc height is decreased.

\section{Statistical analysis}

Grade of disc degeneration were compared between low $\mathrm{T} 1$ group and high $\mathrm{T} 1$ group using $t$-test and chi-square test. And risk of high grade degeneration was analyzed using binary logistic regression test controlling age and gender. Statistically significant difference was considered when $p$-value was $<0.05$.

\section{Results}

Average age of low T1 group was $58.69 \pm 4.92$ and that of high T1 group was $60.41 \pm 5.78$. The difference of age between low T1 group and high T1 group was not sta- 
Table 2. Comparison between low T1 group and high T1 group

\begin{tabular}{lccc} 
Variable & Low T1 group (26) & High T1 group (34) & $p$-value \\
\hline Age $(\mathrm{yr})$ & $58.69 \pm 4.92$ & $60.41 \pm 5.78$ & 0.229 \\
Weight $(\mathrm{kg})$ & $62.08 \pm 8.43$ & $61.15 \pm 5.92$ & 0.634 \\
\hline Height $(\mathrm{cm})$ & $161.73 \pm 6.72$ & $163.79 \pm 7.32$ & 0.267 \\
\hline Body mass index $\left(\mathrm{kg} / \mathrm{m}^{2}\right)$ & $23.76 \pm 3.17$ & $22.81 \pm 1.96$ & 0.162 \\
\hline T1 slope $\left(^{\circ}\right)$ & $19.69 \pm 3.65$ & $31.97 \pm 3.96$ & $<0.001$ \\
Cervical lordosis $\left(^{\circ}\right)$ & $15.15 \pm 9.69$ & $23.38 \pm 9.63$ & 0.002 \\
\hline Sex (male:female) & $11: 15$ & $19: 15$ & 0.435 \\
\hline
\end{tabular}

Values are presented as mean \pm standard deviation.

Table 3. Comparison of radiologic parameter on magnetic resonance imaging between low T1 group and high T1 group using $t$-test

\begin{tabular}{lccr} 
Variable & Low T1 group (26) & High T1 group (34) & $p$-value \\
C2-3 & $2.65 \pm 0.49$ & $2.35 \pm 0.77$ & 0.071 \\
C3-4 & $2.50 \pm 0.65$ & $2.32 \pm 0.59$ & 0.275 \\
C4-5 & $2.62 \pm 0.80$ & $2.59 \pm 0.61$ & 0.882 \\
C5-6 & $3.23 \pm 0.77$ & $2.79 \pm 0.73$ & 0.028 \\
C6-7 & $2.81 \pm 0.69$ & $2.32 \pm 0.68$ & 0.009 \\
\hline
\end{tabular}

Values are presented as mean \pm standard deviation.
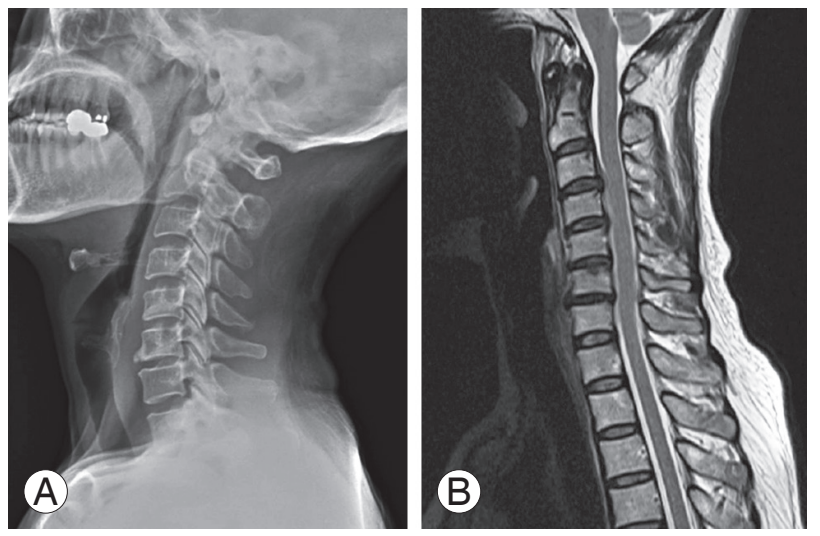

Fig. 1. Radiographic example of a 55-year-old female with low T1 slope (A) upright lateral X-ray. (B) T2 sagittal image of cervical magnetic resonance imaging.

tistically significant $(p=0.229)$. Average $\mathrm{T} 1$ slope of low T1 group was $19.69 \pm 3.65$ and that of high T1 group was $31.97 \pm 3.96$. The difference of $\mathrm{T} 1$ slope between both groups was statistically significant $(p<0.001)$. Average cervical lordosis of low T1 group was $15.15 \pm 9.69$ and that of high T1 group was $23.38 \pm 9.63$. The cervical lordosis of both group was statistically significant $(p=0.002)$. Among both groups, weight, height and body mass index were not significantly different (Table 2).
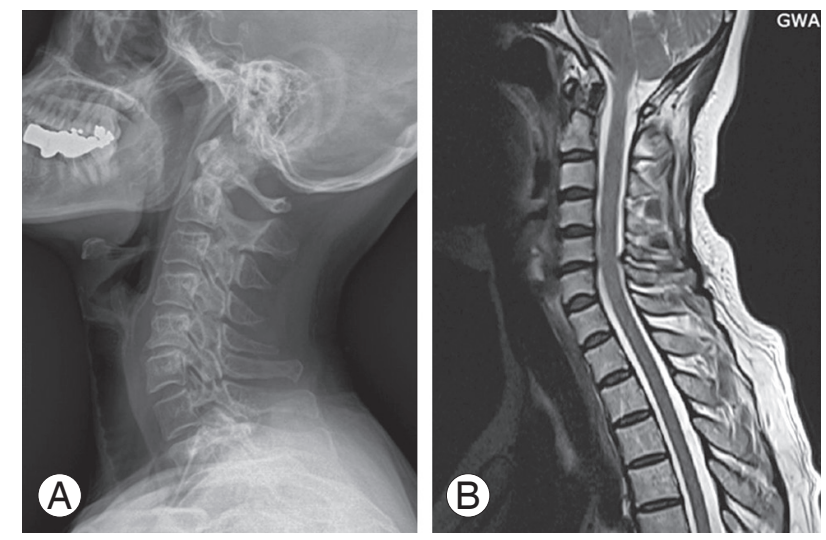

Fig. 2. Radiographic example of a 51-year-old female with high T1 slope (A) upright lateral X-ray. (B) T2 sagittal image of cervical magnetic resonance imaging.

Among low T1 group, average grade of each segment was 2.65 in $\mathrm{C} 2-3,2.50$ in C3-4, 2.62 in C4-5, 3.23 in C5-6, and 2.81 in C6-7; and that of high T1 group was 2.35 in $\mathrm{C} 2-3,2.32$ in C3-4, 2.59 in C4-5, 2.79 in C5-6, and 2.32 in C6-7. Grade of degeneration of low T1 group was significantly higher, as compared with high $\mathrm{T} 1$ group in C5-6 ( $p=0.028)$ and C6-7 ( $p=0.009)$ (Table 3, Figs. 1, 2).

Percentage of high grade degeneration of more than grade III was $65.4 \%$ in the low $\mathrm{T} 1$ group and $32.4 \%$ in 
Table 4. Comparison of radiologic parameter on magnetic resonance imaging between low T1 group and high T1 group using chi-square test

\begin{tabular}{lccc} 
Variable & Low T1 group (26) & High T1 group (34) & $p$-value \\
C2-3 (high grade) & $9(34.6): 17(65.4)$ & $20(58.8): 14(41.2)$ & 0.074 \\
C3-4 (high grade) & $15(57.7): 11(42.3)$ & $23(67.6): 11(32.4)$ & 0.589 \\
C4-5 (high grade) & $13(50.0): 13(50.0)$ & $14(41.2): 20(58.8)$ & 0.603 \\
C5-6 (high grade) & $5(19.2): 21(80.8)$ & $13(38.2): 21(61.8)$ & 0.157 \\
C6-7 (high grade) & $9(34.6): 17(65.4)$ & $23(67.6): 11(32.4)$ & 0.018 \\
\hline
\end{tabular}

Values are presented as number (\%).

Table 5. Odds ratio of high grade cervical degeneration of C6-7 on magnetic resonance imaging by logistic regression analysis

\begin{tabular}{lccc} 
Variable & Odds ratio & $p$-value & 95\% Confidence interval \\
Low T1 slope $\left(^{\circ}\right)$ & 5.633 & 0.005 & $1.665-19.057$ \\
Sex & 1.698 & 0.395 & $0.502-5.742$ \\
Age & 1.092 & 0.144 & $0.970-1.229$ \\
\hline
\end{tabular}

high T1 group ( $p=0.018$ ) (Table 4). Risk of high grade degeneration of C6-7 was significantly higher in the low T1 group (odds ratio, 5.63; 95\% confidence interval, 1.66519.057; $p=0.005)$ (Table 5).

\section{Discussion}

Cervical disc space narrowing, osteophytes, and disc degeneration are common and increase with aging [9]. The prevalence of abnormal magnetic resonance images of the cervical spine is related to age in asymptomatic individuals. Clinical cervical aging studies have shown that $14 \%$ of asymptomatic subjects younger than 40 years have abnormal MRI scans with an increase to $50 \%$ by 50 years old [13]. Therefore, we enrolled patient aged over 50 years old to analyze disc degeneration.

Cervical lordosis in standing posture in 54 healthy volunteers was $54^{\circ}$ (range, $36^{\circ}-76^{\circ}$ ) [14]. In our study, average cervical lordosis of all patients was $19.82^{\circ}$. Candidates of our study were patients with neck pain and radiculopathy of upper extremities. The average age of patient was 59.67 years. Degenerative change with aging and its underlying pathology may be a contributing factor to decrease in lordosis.

Straightened cervical lordosis causes stress concentration, so cervical lordosis may have a direct impact on cervical spondylosis [15]. In our study, the low T1 group had significantly lower cervical lordosis, as compared with the high T1 group. Decreased cervical lordosis in the low T1 group may cause stress concentration on the C5-6 and C6-7 segments. This stress concentration may result in a higher degree of degeneration of these segments.

The changes in sagittal alignment of the cervical spine affects the kinematics. Consequently, it may cause changes in the segment subjected to maximum load for overall motion and accelerate its degeneration [1]. The increased strain energy density and stress in the vertebral cortex over time may induce the remodeling process according to Wolff's law, leading to the formation of osteophytes [10]. Knott et al. [2] reported that patients with high T1 slope of more than $25^{\circ}$ can have positive sagittal balance because of the increased sacral vertical axis.

We did not evaluate whole sagittal balance of body because this study was performed retrospectively. However, high T1 slope does not contribute to a high grade of degeneration of the cervical disc. Cervical degeneration and spondylotic change may be caused by stress concentration with decreased cervical lordosis rather than impaired sagittal balance.

The limitation of our study is that the sagittal balance of patients was not evaluated because the study was performed retrospectively. Degree of disc degeneration of both groups was significantly different but we could not conclude that the sagittal balance has an effect on cervical disc degeneration. Further study is required on the relationship between sagittal balance and cervical disc degeneration. 


\section{Conclusions}

Patients with low T1 slope had less cervical lordosis than patients with high T1 slope. In addition, there was a higher grade of degeneration regardless of age and gender. Low T1 slope is a potential risk factor of cervical spondylosis especially in the C6-7 cervical segment.

\section{Conflict of Interest}

No potential conflict of interest relevant to this article was reported.

\section{References}

1. Miyazaki M, Hymanson HJ, Morishita Y, et al. Kinematic analysis of the relationship between sagittal alignment and disc degeneration in the cervical spine. Spine (Phila Pa 1976) 2008;33:E870-6.

2. Knott PT, Mardjetko SM, Techy F. The use of the T1 sagittal angle in predicting overall sagittal balance of the spine. Spine J 2010;10:994-8.

3. Kim TH, Lee SY, Kim YC, Park MS, Kim SW. T1 slope as a predictor of kyphotic alignment change after laminoplasty in patients with cervical myelopathy. Spine (Phila Pa 1976) 2013;38:E992-7.

4. Park MS, Moon SH, Lee HM, et al. The effect of age on cervical sagittal alignment: normative data on 100 asymptomatic subjects. Spine (Phila Pa 1976) 2013;38:E458-63.

5. Cote P, Cassidy JD, Yong-Hing K, Sibley J, Loewy J. Apophysial joint degeneration, disc degeneration, and sagittal curve of the cervical spine. Can they be measured reliably on radiographs? Spine (Phila Pa 1976) 1997;22:859-64.
6. Dai L. Disc degeneration and cervical instability. Zhonghua Wai Ke Za Zhi 1999;37:180-2.

7. DePalma AF, Rothman RH, Levitt RL, Hammond NL 3rd. The natural history of severe cervical disc degeneration. Acta Orthop Scand 1972;43:392-6.

8. Friedenberg ZB. Degeneration of the Cervical Disc. West J Surg Obstet Gynecol 1964;72:191-4.

9. Gruber HE, Phillips R, Ingram JA, Norton HJ, Hanley EN Jr. Spontaneous age-related cervical disc degeneration in the sand rat. Clin Orthop Relat Res 2014;472:1936-42.

10. Kumaresan S, Yoganandan N, Pintar FA, Maiman DJ, Goel VK. Contribution of disc degeneration to osteophyte formation in the cervical spine: a biomechanical investigation. J Orthop Res 2001;19:977-84.

11. Sambrook PN, MacGregor AJ, Spector TD. Genetic influences on cervical and lumbar disc degeneration: a magnetic resonance imaging study in twins. Arthritis Rheum 1999;42:366-72.

12. Miyazaki M, Hong SW, Yoon SH, Morishita Y, Wang JC. Reliability of a magnetic resonance imagingbased grading system for cervical intervertebral disc degeneration. J Spinal Disord Tech 2008;21:288-92.

13. Boden SD, McCowin PR, Davis DO, Dina TS, Mark AS, Wiesel S. Abnormal magnetic-resonance scans of the cervical spine in asymptomatic subjects. A prospective investigation. J Bone Joint Surg Am 1990;72:1178-84.

14. Gomez Espindola JC, Perez Viquez AF. Cervical lordosis evaluation in asymptomatic volunteers from Navy Medical Center. Acta Ortop Mex 2008;22:7-11.

15. Wei W, Liao S, Shi S, Fei J, Wang Y, Chen C. Straightened cervical lordosis causes stress concentration: a finite element model study. Australas Phys Eng Sci Med 2013;36:27-33. 